$\mathrm{F}$

$40,15 / 16$

40

Received 6 April 2021

Revised 21 June 2021

Accepted 1 August 2021

\section{Smart workplace solutions - can they deliver the offices that employees have been waiting for?}

\author{
Laura Remes
}

Department of Electrical Engineering and Automation, Aalto University, Espoo, Finland

Kenneth Dooley

Department of Electrical Engineering and Automation, Aalto University, Espoo, Finland and Empathic Building, Haltian, Helsinki, Finland

Jaakko Ketomäki

Department of Electrical Engineering and Automation, Aalto University, Espoo, Finland and Sustainable Construction and Real Estate, Motiva Ltd., Helsinki, Finland, and

Heikki Ihasalo

Department of Electrical Engineering and Automation, Aalto University, Espoo, Finland and Innovations, Granlund Oy, Helsinki, Finland

\begin{abstract}
Purpose - User-centred intelligent buildings (IBs) should respond to users' needs holistically and the demand for end user applications is steadily growing. The purpose of this study is to answer: What are end user applications, what should they be called, and what are their key features?

Design/methodology/approach - This is a mixed-method study. The authors have used different data sources, such as online research and interviews. In data processing, the authors have used word counting and Latent Dirichlet Allocation topic modeling.

Findings - These end user applications can provide the missing user-centered elements of IBs. The authors have found that "smart workplace solution" (SWS) is the best term to describe these applications, and they also describe the key features, which include booking, showing free spaces, occupancy tracking, wayfinding and searching.

Research limitations/implications - As the end user applications are constantly and rapidly evolving, the latest evolving of such applications might not be covered. Furthermore, the authors have relied on companies' information as given.

Originality/value - IBs have emerged over 20 years ago, and these are the first solutions that can be considered truly user-centered.
\end{abstract}

Keywords Office buildings, Smart workplace solutions, Smart office, Intelligent buildings, Smart buildings

Paper type Research paper

(C) Laura Remes, Kenneth Dooley, Jaakko Ketomäki and Heikki Ihasalo. Published by Emerald Publishing Limited. This article is published under the Creative Commons Attribution (CC BY 4.0) licence. Anyone may reproduce, distribute, translate and create derivative works of this article (for both commercial and non-commercial purposes), subject to full attribution to the original publication and authors. The full terms of this licence may be seen at http://creativecommons.org/licences/by/4.0/legalcode 


\section{Introduction}

A wide variety of definitions for intelligent buildings (IBs) have been presented in the literature (Dakheel et al., 2020; Wong et al., 2005). They are also known as smart buildings (SBs) (Buckman et al., 2014; Dakheel et al., 2020), but we have chosen to use the more commonly used term in our references: intelligent building. IBs were originally termed as "intelligent" if they contained electronic enhancements (Omar, 2018). IBs present a new type of technological architecture and an environment where new technological applications and innovations can be deployed (Kroner, 1997). IBs use combinations of various technologies, ranging from material technologies and electronics to artificial intelligence (AI) (Apanaviciene et al., 2020; Jia et al., 2019). Furthermore, making buildings more intelligent is a means of improving the sustainability and increasing the energy efficiency of buildings by using new emerging technologies and innovations. This provides economic and ecological benefits (Apanaviciene et al., 2020; Ghaffarianhoseini et al., 2017).

Over the past three decades, growing interest in IBs has led to the founding of both national and international organizations (Kroner, 1997), as well as plans by the European Commission to introduce legislation and a metric for classifying the intelligence or "smartness" of buildings (Verbeke et al., 2020). For this purpose, the European Commission has developed, in collaboration with European research organizations, the Smart Readiness Indicator (SRI) (Verbeke et al., 2020). The SRI defines the "smartness" of buildings in terms of three metrics:

(1) energy efficiency;

(2) grid flexibility; and

(3) adaptation to users' needs (Verbeke et al., 2020).

It is the importance of the latter, users' needs, that is highlighted in this article. We have chosen to use the SRI as the main guideline, because there are plans to transpose it into the legislation of European Member States, although it is currently a voluntary scheme (Verbeke et al., 2020).

Traditionally, IBs have focused on how technology can improve the operations of a building instead of the impact of the IB on human occupants (Omar, 2018). IBs are typically comprised of sensors, controllers and software related to alerts and fault detection, building technical performance analysis and automation (Clements-Croome, 1997; Kroner, 1997). From these foundations, IBs have gradually developed into interactive, dynamic and responsive dwellings with multiple integrated features (Apanaviciene et al., 2020; Rönka, 2019). Such buildings have evolved into a concept that is no longer just a building, but something more, hence a prefix, such as "intelligent" or "smart", is needed to properly describe them and distinguish them from traditional buildings (Omar, 2018).

In the 1990s, Kroner (Kroner, 1997) redefined the IB in terms their "intelligence of design". Intelligent buildings need technology to be specified during the design stage that enhances the functional needs of the building. They also need this technology to be used and maintained correctly during the occupancy phase (Kroner, 1997). This introduces the importance of intelligent building technology to facility management processes (Bröchner et al., 2019).

It is already been recognized that IBs should enable the users to maximize their full potential and to provide an adequate indoor environment or micro-climate (Aksoy and Uzunogly, 2020; Horr et al., 2016; Mofidi and Akbari, 2017, 2020). Furthermore, users' productivity and comfort should be maximized by IB solutions while still considering the related operating costs (Aksoy and Uzunogly, 2020; Apanaviciene et al., 2020; Mofidi and Akbari, 2016, 2020). The idea of the holistic nature of IBs has also emerged in literature 
$\mathrm{F}$

$40,15 / 16$

(Abisuga et al., 2019; Himanen, 2004; Rawte, 2017). Nevertheless, the profound change for IBs to become truly holistically human-centered is still under development.

In the SRI framework, the adaptation to users' needs is defined in terms of four attributes: comfort, convenience, promoting health and well-being, as well as the building's ability to provide information to occupants (ItO) (Verbeke et al., 2020). Comfort refers to the occupants' reactions to environmental conditions, such as the temperature, lighting and noise level. Convenience is related to making occupants' lives easier. Health and well-being concerns not only maintain health and well-being but also promote and enhance it. The last attribute, ItO, describes the information provided by the building regarding its functions and operation (Verbeke et al., 2020). The inclusion of convenience and ItO means that the SRI takes into consideration aspects that have traditionally been overlooked or have received little attention.

In this paper, the aspects of IBs that we are interested in are the benefits, which can be gained by humans as users (also known as occupants) of those buildings. As has been discussed above, the previous studies in this field have primarily focused on the operational performance of building components such as energy, security and indoor conditions. This is covered by comfort and health and well-being in the adaptation to users' needs sections of the SRI.

The other elements of the SRI that are related to users' needs, convenience and information for users, are very different from the traditional focus of the field. The previous engineering dominant approach has focused on making sure that the systems work correctly and efficiently. They have aimed to make sure that there is for example adequate lighting, drinkable water and suitable indoor temperatures. However, the concept of making the lives of the occupants easier has not been adequately studied. Human capital has been acknowledged and become of great value in recent decades, especially in the field of knowledge work (Rönka, 2019). Companies are interested in intelligent building solutions related to helping occupants rather than just ensuring that the building functions. In the past, solutions that have aimed to improve productivity or employee performance has focused on indoor conditions; however, there is a growing demand to go beyond this and to focus on elements such as employee experience and happiness (Rönka, 2019). One key driver for this is that in many knowledge organisations, costs related to staff are approximately $90 \%$ of total business operating costs (Alker et al., 2015). We intend to go beyond indoor conditions and already known productivity-enhancing factors by introducing how to overcome productivity-hindering factors and emphasize the experience side of IBs. Even the Honeywell Smart Building Score considers productivity as one of the main aspects of IBs (Honeywell International Middle East Ltd, 2016).

End user applications can help IBs to become more user-centered. For that reason, we have studied these kinds of applications. We have aimed to answer to two questions: What should these end user applications be called, and what are their most relevant features?

\section{User-centered}

We have chosen to use the term "user-centered" to describe the user benefit side of IBs. It is the most common term in 80 relevant papers from highly regarded journals in the field of real estate and building automation that we have studied. Other words describing the user are "human" and "people". Instead of "centered", "centred", "centric" and "oriented" are also used. A total of $58 \%$ of the papers we have studied had the word "user" and $38 \%$ had "centered". A total of $80 \%$ had a hyphen in them and thus we have used the hyphenation as well.

For a user to benefit from an IB, the IB concept should be further developed to ensure that it will respond to the user's needs (Apanaviciene et al., 2020). Such development has been an 
important goal for today's IBs (Aksoy and Uzunogly, 2020; Apanaviciene et al., 2020). This article follows the approach of the SRI and the four attributes of user's needs are comfort, health and well-being, convenience and ItO and have found that the majority of the development has focused on the first two attributes. To date, there has been a lack of progress in improving the convenience and ItO attributes which aim to make IBs easy to use and to save time for occupants (Rönka, 2019; Xu et al., 2019).

The development of IBs has traditionally focused on office buildings (Kroner, 1997), as will this paper. The emergence and growth of knowledge work are transforming the built environment to serve its needs (Kroner, 1997). Furthermore, companies seek to use the best intellectual capital available as well as to nurture this investment. This is because intellectual capital is often the source of inventions and innovations, which in turn brings economic benefits to the company (Harter et al., 2003; Rönka, 2019). The traditional user-centered approach does make sense, as for knowledge workers to be as productive as possible, their personal well-being and comfort preferences should be taken into consideration (Aksoy and Uzunogly, 2020; Chwalbińska-Kusek et al., 2015; Clements-Croome, 2004;). Adaptive automation and the feeling for higher personal control creates greater satisfaction amongst building users (Ahmadi-Karvigh et al., 2019; Froufe et al., 2020; Leaman and Bordass, 1999). The digitalization of IBs has made it possible to extend personal control of employees to other areas as well, which adds to the convenience and reducing friction in the workplace (Rönka, 2019). The reduction of friction refers to the elimination or decrease of productivity-hindering factors, which include extra complications and the loss of time due to distractions and secondary work tasks, e.g. finding and booking an appropriate meeting room (Clements-Croome, 2015; Haynes, 2007, 2008; Rönka, 2019). Thus, the reduction of friction adds to productivity (Clements-Croome, 2015; Haynes, 2007, 2008). In addition, IB technologies increase the value of buildings and produce lower costs of operation and maintenance which enables them to be economically sustainable (Berawi et al., 2017; Omar, 2018; Rönka, 2019). For these reasons, the importance and value of technologies and services of IBs have become increasingly important in recent decades (Rönka, 2019; Tham, 2016).

However, we need to go beyond the traditional user-centered approach and to also focus on convenience and ItO. This is especially true concerning office buildings where knowledge work is done and staff costs are a high percentage of total operating costs (Alker et al., 2015). To help companies to nurture their employees, new technology solutions such as end user applications has emerged following the evolution Internet of Things (IoT) solutions and smartphones (Dong et al., 2019; Miorandi et al., 2012). Holistic solutions are needed to increase users' well-being and health and this includes the management of the IB, the services provided in it and the end user applications (Apanaviciene et al., 2020; Obrecht et al., 2019). Furthermore, these end user applications make users' lives easier (Apanaviciene et al., 2020). They help employees work-life by increasing convenience factors, reducing friction and providing more efficient use of time, which further benefits companies economically and ecologically (Haynes, 2007, 2008; Rönka, 2019). In addition, end user applications promote employee engagement and support the workplace culture by improving workplace experience, which in turn promote co-operation and togetherness for the benefit of the company (Harter et al., 2003; Rönka, 2019). The end user applications also fulfil the employee's desire to have an individualized workplace (Barrett and Barrett, 2010). The balance between social and solitary work is vital for employee's well-being (Heerwagen et al., 2004) and end user applications can support this. Well-being can also refer to mental health and happiness (Clements-Croome, 2015), and the increase of well-being is one of the main goals of end user applications. Thus, they enlarge the concept of IB and provide new business possibilities. Hence, a vast amount of end user applications providing such services have emerged in a short amount of time. For this paper, we have studied such applications and 
$\mathrm{F}$

$40,15 / 16$

chosen the 33 most relevant applications for further consideration. The goal is to finally end the debate on what those applications should be called and what are their main features.

\section{Methodology}

Our research is based on two research questions: what should these end user applications be called and what are their most common features? We have used mixed methods approach which combines quantitative and qualitative methods in our research. Our approach utilized online research, non-probability and snowball sampling to find the most relevant solutions. In our online research, we have used pre-selected keywords and their combinations while using Google as our search engine. We have also conducted research interviews.

The first step was to search for the existing IB solutions that were focused on end users and could be described as end user applications in the context of IBs. The online research used specific keyword criteria for our non-probability sampling. Those were broken down into three different groups (Table 1). The first group included adjectives describing smartness: smart and intelligent. Words in the second group described the physical place: office, facility management and building. Our main focus was on office buildings, but also facility management companies have created similar applications, so we included them as well. We focused on office buildings as end user applications are closely related to improving employee performance and user satisfaction. The combination of these elements is well suited to office buildings. As mentioned above, costs related to staff are approximately $90 \%$ of total business operating costs for knowledge organizations (Alker et al., 2015). The third group was about the application: application, mobile application, app, mobile app. The online research was done by combining words from all of the groups $1-3$.

To a comprehensive list of solutions we also used snowball sampling in our research by asking our interviewees to provide the names of their closest competitors. Furthermore, when we found a solution that met our criteria, we searched for companies that described themselves in the same way. After finding the most relevant companies, we collected comparable data from their websites and we also conducted interviews to get an in-depth understanding of applications.

In all, three in-depth interviews were conducted. The interviewed companies were District Technologies, Rapal and Haltian Emphatic Building. All of the interviewed companies presented different industry categories to get a wider range of companies. District Technologies are concerned with community management and engagement, Rapal focus on facilities management software and Haltian is mostly concerned with employee experience. District Technologies are from the UK and the other two companies are from Finland. All of the interviews consisted of the same questions. There were two sets of questions: open and binary "yes" or "no" questions. The open questions were related to the background of the interviewee, the background of the company and how they descried their solution. The binary questions were related to the features that were included in the solution.

We aimed to determine what these emerging group of solutions should be called and to uncover their most common features. A simple framework illustrating the methodology can be seen below (Figure 1).

Table 1.

Keywords for online research

\begin{tabular}{llll}
\hline Group & 1 & 2 & 3 \\
\hline Keywords & Intelligent, & Office, & Application, \\
& Smart & Office building, & Mobile application, \\
& Building, & App, \\
& Facility management & Mobile app \\
\hline
\end{tabular}




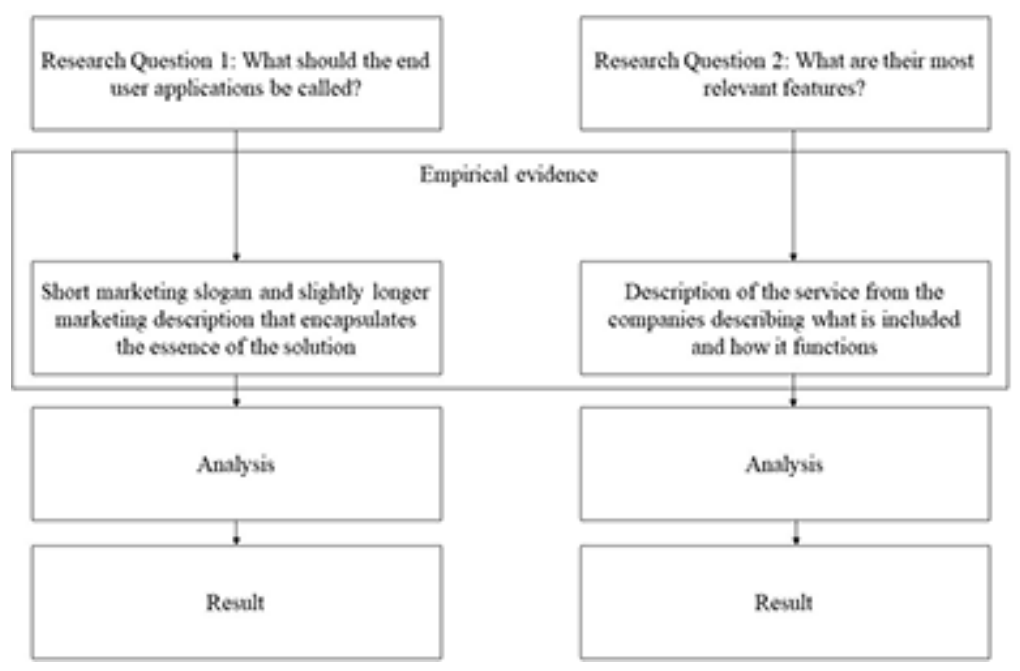

Smart workplace solutions

\subsection{RQ1: What should these end user applications be called?}

The end user application providers describe their products in their websites and documents. For that reason, we collected their short marketing slogans as they encapsulate the products. Furthermore, we collected slightly longer marketing description (MD) to get more in-depth descriptions than shorter slogans. In addition to slogans, MDs offered a wider selection and a more comprehensive database of most commonly used words describing them. All of the slogans and MDs were collected from chosen companies' websites as they were in May 2020.

The occurrence of words in slogans and MDs were arranged into four groups. In the first group is the occurrence of words in slogans and in the second group the occurrence in MDs. Furthermore, two other groups have been created. The third group considers the occurrence of words in both slogans and MDs. The last group consists of the occurrence of words in either slogans or MDs. In all of the four groups are the number as well as the percentage of companies having those words in slogans and/or MDs.

The companies commonly used a combination of three words to describe applications themselves and thus our name is also a three-word term. The first word-set, which is an adjective, is needed to describe the application and its smartness. The second word-set describes the place where the SWS is used, e.g. office. The third word-set describes the technology itself, e.g. application. Furthermore, we collected a random set of words, which were seen as relevant in LDA topic modeling (Table 2). We organized the most relevant words in the topic modeling style explained later on to already mentioned word sets (Table 2).

\begin{tabular}{lllll}
\hline Adjective & Subjective & Technology & Random & Table 2. \\
\cline { 1 - 2 } Smart, & Workplace, & Platform, & Experience, & An example of word \\
Better & Office, & Solution, & Management, & Anats for the term \\
& Space, & App, & Employee, & describing end user \\
& Workspace, & Technology & Meeting, & applications \\
& Building & & Visitor & apd \\
\hline
\end{tabular}


$\mathrm{F}$

$40,15 / 16$
After collecting the slogans and the MDs of all the companies, we studied the prevalence of different words in slogans and MDs and we organized them to find out the synonyms. Furthermore, we used the Latent Dirichlet Allocation (LDA) topic modeling to determine the most suitable term for the end user applications. It is a generative probabilistic model, which is used to find the most relevant topics from text documents (Blei et al., 2003). For the coding, Python language was used. By combining the prevalence of different synonyms, topic modeling and eliminating the synonyms, we concluded on the most suitable way to describe end user applications.

\subsection{RQ2: What are the most common features of these application?}

Binary questions, with answers "yes" or "no", were used to analyse the companies that were included in this research. Most of the data were collected from companies' Webpages, which provided information about what was included in their end user applications and how they worked. In three cases, information was confirmed by interviews. Answers to those binary questions were collected to a single Excel file. Overall, 36 smart features were identified. Those are as follows: booking, free spaces, occupancy, wayfinding, search box, unattendance, incident reporting, people flow, calendar sync, indoor environment quality (IEQ), equipment, hospitality, building performance, room displays, asset tracking, space releasing, IEQ remote control, digital keys, IEQ feedback, lunch menu, financial performance, parking spaces, scheduling assistance, event information, room service, wellness analytics, parking analytics, personal layout, work time, concierge service, property management, cleaning management, maintenance planning, service quality, payment possibility and lunch queue. The final check of the Excel data was done in May 2020 and is based on the information that was available then.

\section{Results}

\subsection{Results from the slogans and short descriptions}

From our study of word prevalence in slogans and MDs, we collected the data to an Excel file. The most relevant results are in Table 3 . Both irrelevant and most of the words, which had the occurrence of less than 5\% of companies' slogans and MDs, were left out. Exceptions are the words, which were relevant in collecting synonyms describing the end user applications. In addition, inflected forms, e.g. unit and plural forms, of the same words were combined to avoid overlaps.

The results from the word occurrences in slogans and MDs and LDA modeling of word sets (Figure 2) are based on most common words in slogans and MDs. The results are based on actual word occurrences, as LDA topic modeling is based on the probabilities of occurrence of words rather than exact percentages of occurrence (Blei et al., 2003). Nevertheless, LDA topic modeling helped us to identify which words were the most appropriate in each word set. In addition, it serves as a visual presentation of our research results. For the adjective "smart" was most probable, for the adjective "workplace" and for the technology "solution". From those, we concluded that the best term to describe the end user application is "smart workplace solution"(SWS), which is the answer to the first research question. As was our aim, we have found a suitable term to describe the end user applications. It can be seen in the word cloud created by LDA topic modelling (Figure 2).

\subsection{Results from the binary questions}

We have divided the results of 36 "yes" or "no" questions into different layers of features based on the frequency of their occurrence. The most relevant features make up the core. After that comes layers 1, 2 and 3 (Figure 3). The rest of the features are not included due to 


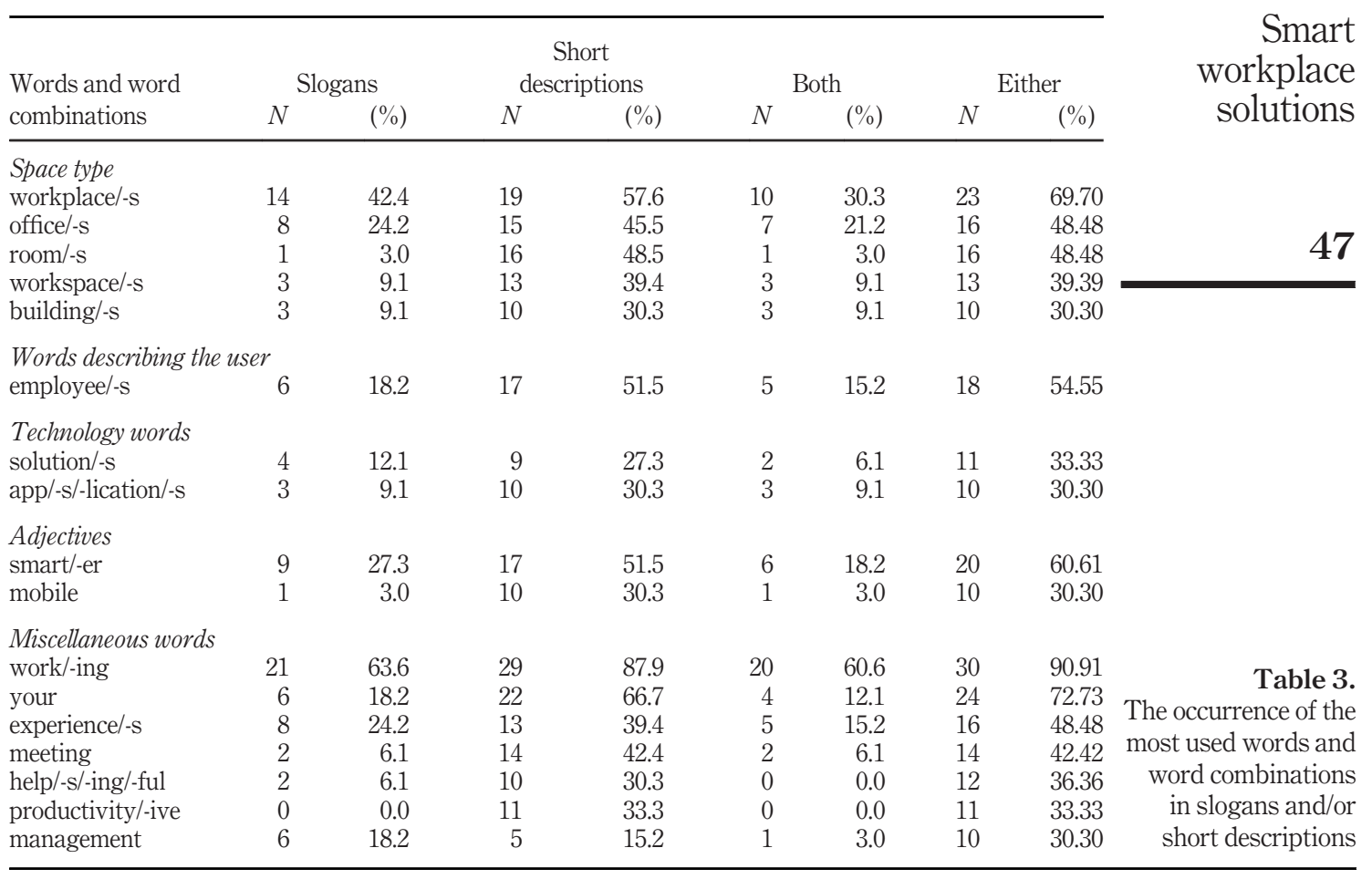

their minimal occurrence in the SWSs that have been studied. We have added the features, that were present in at least $75 \%$ of the companies to the core. There are five of them and they are booking, free spaces, occupancy, wayfinding and search box (Figure 3). The next five features, which are present in at least $45 \%$ of companies are included in the first layer. They are unattendance, incident reporting, people flow, calendar sync and IEQ (Figure 3). The second layer also has six features, which are: equipment, hospitality, building performance, room displays, asset tracking and space releasing (Figure 3). The rest of the features are included in the third layer.

The core features require a deeper examination as they are the main answer to the second research question. Booking refers to a user interface (UI) where office users can book a desk or a room. Free spaces mean that the availability of spaces, whether rooms or desks, are shown in real-time. Occupancy concerns real-time occupancy data and analytics aimed at managers. Wayfinding refers both to indoor navigation and other kinds of wayfinding features in UI. Wayfinding is also known as indoor localization (Deak et al., 2012; Jia et al., 2019). We have chosen to use wayfinding as it is a more common term based on our collection of slogans and MDs. The search box in the UI is meant for searching for the location of rooms and people.

Our second aim of this study was to find out, which are the most relevant features in the SWSs. We also achieved this goal as we have got clear results, which are the core features of SWSs, and what other kind of features are quite common in SWSs as described when discussing other layers. 
F

40,15/16

48

Figure 2.

The word cloud by

LDA topic modeling

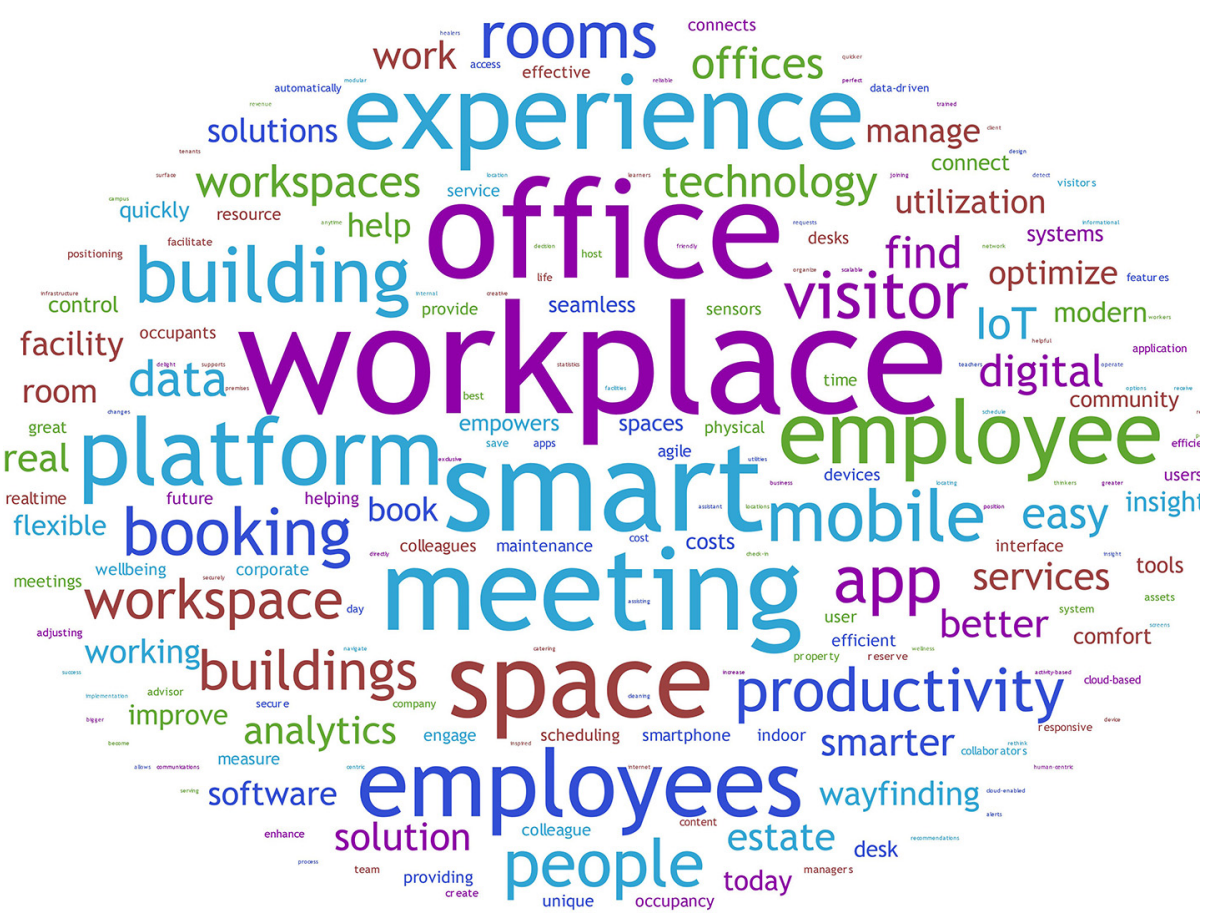

The core

Booking

Free spaces

Occupancy

Wayfinding

Layer 1

Search box

Unattendance

Incident reporting

People flow

Layer 2

Equipment

Hospitality

Building performance

Room displays

Asset tracking

Space releasing
Figure 3.

The core and two layers 


\section{Discussion}

The concept of user-centered IBs is evolving and there are two distinct focus areas. Using the categories of the SRI, we see that one focus area follows the traditional approach which is mostly concerned with comfort and health and well-being and an emerging approach concerned with convenience and ItO (Verbeke et al., 2020). Convenience and ItO have received relatively little attention and this article aims to shine more light on them. This way IBs can move further away from the engineering dominant approach towards a more balanced approach that balances operational performance and user-centered.

The core features, and thus the most important, of the SWS's are those that appear most frequently across the applications offered by the 33 different companies. These features are related to how the users interact with spaces and include: searching, showing free spaces, wayfinding, booking and reporting the space efficiency. Hence, it could be said that the "smartness" of workplaces is to make life easier for employees in terms of key friction effects, which include space booking and wayfinding. Workplace friction refers to productivity-hindering factors, which include extra complications and the loss of time due to distractions and secondary work tasks. The SWS features commonly relate to saving time by quickly finding a suitable space, navigating to the place you need to be and not being lost and finding colleagues. The features go beyond traditional elements such as comfort and user satisfaction (Kwon and Remøy, 2019). They highlight the convenience and ItO aspects of SWSs, which have been traditionally overlooked in IBs, by being easy to use and saving time for occupants (Rönka, 2019; Xu et al., 2019). Indeed, SWSs expand the concept of IB to be all inclusive. Furthermore, a smart space booking system with wayfinding allows the reduction of space and costs in organizations without compromising user's well-being (Dooley, 2017), and thus adds a bonus layer to the user-centered aspect of the IBs.

There were relevant findings regarding the occurrence of specific words in slogans and MDs. As space booking is relevant to meeting arrangements, it is no surprise that the word "meeting" is used in $42.42 \%$ of SWS slogans and MDs. SWSs help employees in their everyday work life (Apanaviciene et al., 2020; Rönka, 2019), and the word "help" is present in $36.36 \%$ of slogans and MDs and the word "work" in $90.91 \%$. That emphasizes the importance of convenience and ItO. It is surprising that words "booking", "efficiency", "wayfinding" and "navigation" are present in less than one quarter of slogans and MDs per cents being $24.24 \%, 21.21 \%, 15.15 \%$ and $9.09 \%$ even though they are words describing the most relevant features of SWSs. Furthermore, "management" is used in $30.30 \%$ of SWS slogans and MDs, which is no surprise as SWSs serve management as well as users (Apanaviciene et al., 2020; Omar, 2018; Xu et al., 2019).

Based on our study, it is clear that SWSs are predominately software solutions and less focused on traditional elements hardware components or measuring the indoor climate. For example, the abbreviation "IoT" is present in $27.27 \%$ of slogans and MDs, but the word "sensor" is present only in $15.15 \%$ and "device" in $12.12 \%$. Furthermore, words relevant to the indoor climate e.g. "heating" and "lighting" are present only in $6.06 \%$ of slogans and MDs.

There were additional findings regarding the most common words in slogans and MDs. The word "your" was present in $72.73 \%$ of slogans and MDs and "experience" in 48,48\%. It supports the notion that SWSs are about the personal experience (Apanaviciene et al., 2020; Rönka, 2019); and not just about comfort, health and well-being, which have traditionally implied to physical aspects instead of mental. Furthermore, the words "help" and "productivity" are common as they are in $33.33 \%$ of slogans and MDs. Especially "help" refers to convenience. As those words imply, SWSs object is to help employees to be more productive while present in their workplace (Apanaviciene et al., 2020; Rönka, 2019), and 
$\mathrm{F}$

$40,15 / 16$

that happens by adding to convenience and ItO. Thus, it was surprising that the word "userfriendly" was present only in $6.06 \%$ of slogans and MDs and "human-centric" in $3.03 \%$. Furthermore, other forms of the same meaning terms were not present at all, including the most relevant term "user-centered". A notable increase in their use in the future would be a logical continuation of the current trend.

We suggest that companies providing SWSs would start to use the term "user-centered" or similar terms with the same meaning in their solution descriptions. Furthermore, we highly recommend that all of the key features would be present in the SWSs or if lacking, would be added to the solutions for them to stay relevant and to stay in the market. In our view, first SWS companies to seize these proposals may potentially gain an advantage to remain in the market as competitors are eliminated. As personalized indoor environments are part of the future IBs (Wang et al., 2017), we believe, that SWSs are here to stay and are a productive business. That adds to the importance of this study.

\section{Conclusions}

Despite all of the development that has occurred in the field of IBs, user-centered solutions have been largely neglected. Traditional focus areas have been comfort, health and wellbeing, but convenience and $\mathrm{ItO}$ have not been sufficiently covered. In this paper, we have introduced SWSs to the scientific literature which help to fill that gap. They have the potential to dramatically enhance the user-centricity of IBs, especially by adding to the missing focus areas. SWSs are paving the road to the future as they add those increasingly user-centered elements to IBs as well as social elements. Comfort and health and well-being are embedded in the traditional engineering dominant approach. They relate to keeping people warm, to having enough light or air for ventilation. SWS bring user-centered features that are furthest from the traditional path of IB development and focus on being easy to use and making life in the office building convenient by saving time, helping employees to avoid getting lost and finding their colleagues. Building managers can also analyse which spaces and desks are most popular and use the data to remove unpopular spaces and replace them with ones that are more in demand. This might mean for example, reducing the number of 10 person meeting rooms and increasing the number of phone booths or small two-person meeting rooms. This is also a user-centered approach as the managers use the data from the SWS to co-create the space offering with the employees using the space.

This study had two parts. The first part was to find out how to describe SWSs. The second was to conclude, which features are most relevant in SWSs. Our results were derived from various descriptions and data of the most relevant features of the SWSs. From the descriptions by using word count and LDA topic modeling we found the term "smart workplace solution" as the best way to describe SWSs. The most relevant features of SWSs are as follows: booking meetings and spaces; finding free spaces; occupancy data and analytics; wayfinding (or indoor navigation); and a search box for spaces, tools, people, etc. Those features emphasize the importance of the missing focus areas concerning IBs thus filling a gap and making IBs holistically user-centered. It highlights the importance of our study.

In this paper, we have defined SWSs, including what they should be called and most common features. It finally ends the debate of terminology and gives a clear answer to what these end user applications for indoor working environments should be called. Furthermore, our study shows the industry what features are most relevant in SWSs because they are the most common features and appear in at least $75 \%$ of the applications offered by the 33 companies studied. It helps the development of SWSs and helps companies to choose, which 
kind of SWS they should use to stay at the forefront of user-centered IBs. Our study lays the foundation for how user-centered future workplaces are.

We acknowledge that these kinds of state-of-the-art solutions are primarily relevant in developed countries. The other limitation of this study is that there is a limit to the amount of SWSs that we have covered. More of them could be found. Furthermore, the field is constantly and rapidly developing, and the latest upgrades have not been taken into consideration. SWSs have been used to show practical and real world examples of human centered smart building technologies. Further research is needed to adequately explore this phenomenon of human centered SBs and how it is compares to the previous engineering dominant approach which focused primarily on operational performance of building. This article uses the SRI as an IB reference which discusses user-centered elements in detail, but a more detailed review of IB features that range from the traditional to convenience and ease of use would be of benefit. Another element of further study is related to health and wellbeing. This study discusses health and well-being in the context of IBs as defined by the SRI. This definition of health and well-being is mostly concerned with physical health and well-being and future studies should also consider the mental and social components of workplace well-being.

\section{References}

Abisuga, A.O., Wang, C.C. and Sunindijo, R.Y. (2019), "A holistic framework with user-centred facilities performance attributes for evaluating higher education buildings", Facilities, Vol. 38 Nos 1/2, pp. 132-160.

Ahmadi-Karvigh, S., Becerik-Gerber, B. and Soibelman, L. (2019), "Intelligent adaptive automation: a framework for an activity-driven and user-centered building automation", Energy and Buildings, Vols 188/189, pp. 184-199.

Aksoy, M. and Uzunogly, S.S. (2020), "Assessment of user satisfaction in an intelligent office building in Istanbul”, Journal of Facilities Management, Vol. 18 No. 3, pp. 325-340.

Alker, J., Malanca, M., Pottage, C. and O'Brien, R. (2015), "Health, Wellbeing and Productivity in Offices - the Next Chapter for Green Building, World Green Building Council.

Apanaviciene, R., Vanagas, A. and Fokaides, P.A. (2020), "Smart building integration into a smart city (SBISC): development of a new evaluation framework", Energies, Vol. 13 No. 9, pp. 1-19.

Barrett, P. and Barrett, L. (2010), "The potential of positive places: senses, brain and spaces", Intelligent Buildings International, Vol. 2 No. 3, pp. 218-228.

Berawi, M.A., Miraj, P., Sayuti, M.S. and Berawi, A.R.B. (2017), "Improving building performance using smart building concept: benefit cost ratio comparison”, AIP Conference Proceedings, Vol. 1903 No. 1.

Blei, D.M., Ng, A.Y. and Jordan, M.I. (2003), "Latent Dirichlet allocation”, Journal of Machine Learning Research, Vol. 3, pp. 993-1022.

Bröchner, J., Haugen, T. and Lindkvist, C. (2019), "Shaping tomorrow's facilities management", Facilities, Vol. 37 Nos 7/8, pp. 366-380.

Buckman, A.H., Mayfield, M. and Beck, S.B. (2014), "What is a smart building?", Smart and Sustainable Built Environment, Vol. 3 No. 2, pp. 92-109.

Chwalbińska-Kusek, K., Wójcik, J., Szubert, M., Ciesla, J., Kosonen, R., Targowski, A., Stachowiak, A., Pora, A., Slek, B. and Olszewski, P. (2015), "Health and Productivity in Sustainable Buildings", Construction Marketing Group, BuroHappold Engineering.

Clements-Croome, D.J. (2004), "Intelligent buildings", Intelligent Buildings - Design, Management and Operation, Thomas Telford Publishing, London, pp. 3-24. 
$\mathrm{F}$

$40,15 / 16$

Clements-Croome, D.J. (2015), “Creative and productive workplaces: a review”, Intelligent Buildings International, Vol. 7 No. 4, pp. 164-183.

Clements-Croome, D.J. (1997), "What do we mean by intelligent buildings?", Automation in Construction, Vol. 6 Nos 5/6, pp. 395-400.

Dakheel, J.A., Del Pero, C., Aste, N. and Leonforte, F. (2020), "Smart buildings features and key performance indicators: a review”, Sustainable Cities and Society, Vol. 61, p. 102328.

Deak, G., Curran, K. and Condell, J. (2012), “A survey of active and passive indoor localisation systems”, Computer Communications, Vol. 35 No. 16, pp. 1939-1954.

Dong, B., Prakash, V., Feng, F. and O’Neill, Z. (2019), “A review of smart building sensing system for better indoor environment control”, Energy and Buildings, Vol. 199, pp. 29-46.

Dooley, K. (2017), "Routines, rigidity and real estate: organisational innovations in the workplace", Sustainability, Vol. 9 No. 6, p. 998.

Froufe, M.M., Chinelli, C.K., Guedes, A.L.A., Haddad, A.N., Hammad, A.W.A. and Soares, C.A.P. (2020), "Smart buildings: systems and drivers", Buildings, Vol. 10 No. 9, p. 153.

Ghaffarianhoseini, A., AlWaer, H., Ghaffarianhoseini, A., Clements-Croome, D., Berardi, U., Raahemifar, K. and Tookey, J. (2017), "Intelligent or smart cities and buildings: a critical exposition and a way forward", Intelligent Buildings International, Vol. 10 No. 2, pp. 122-129.

Harter, J.K., Schmidt, F.L. and Keyes, C.L.M. (2003), "Well-being in the workplace and its relationship to business outcomes: a review of the gallup studies", Flourishing: Positive Psychology and the Life Well-Live, American Psychological Association, pp. 205-224.

Haynes, B.P. (2007), "Office productivity: a theoretical framework", Journal of Corporate Real Estate, Vol. 9 No. 2, pp. 97-110.

Haynes, B.P. (2008), "An evaluation of the impact of the office environment on productivity", Facilities, Vol. 26 Nos 5/6, pp. 178-195.

Heerwagen, J.H., Kampschroer, K., Powell, K.M. and Loftness, V. (2004), "Collaborative knowledge work environments", Building Research and Information, Vol. 32 No. 6, pp. 510-528.

Himanen, M. (2004), "The intelligence of intelligent buildings", Intelligent Buildings, Thomas Telford Publishing, pp. 25-52.

Honeywell International Middle East Ltd (2016), "Honeywell smart building score - a smarter tomorrow: buildings. cities. life", available at: http://smartbuildings.honeywell.com/MEhsbs_aboutus (accessed 14 May 2020).

Horr, Y.A., Arif, M., Kaushik, A., Mazroei, A., Katafygiotou, M. and Elsarrag, E. (2016), "Occupant productivity and office indoor environment quality: a review of the literature", Building and Environment, Vol. 105, pp. 369-389.

Jia, M., Komeily, A., Wang, Y. and Srinivasan, R.S. (2019), "Adopting internet of things for the development of smart buildings: a review of enabling technologies and applications", Automation in Construction, Vol. 101, pp. 111-126.

Kroner, W.M. (1997), "An intelligent and responsive architecture”, Automation in Construction, Vol. 6 Nos 5/6, pp. 381-393.

Kwon, M. and Remøy, H. (2019), "Office employee satisfaction: the influence of design factors on psychological user satisfaction”, Facilities, Vol. 38 Nos 1/2, pp. 1-19.

Leaman, A. and Bordass, B. (1999), "Productivity in buildings: the 'killer' variables”, Building Research and Information, Vol. 27 No. 1, pp. 4-19.

Miorandi, D., Sicari, S., De Pellegrini, F. and Chlamtac, I. (2012), "Internet of things: vision, applications and research challenges", Ad Hoc Networks, Vol. 10 No. 7, pp. 1497-1516.

Mofidi, F. and Akbari, H. (2016), "Integrated optimization of energy costs and occupants' productivity in commercial buildings", Energy and Buildings, Vol. 129, pp. 247-260. 
Mofidi, F. and Akbari, H. (2017), "Personalized energy costs and productivity optimization in offices", Energy and Buildings, Vol. 143, pp. 173-190.

Mofidi, F. and Akbari, H. (2020), "Intelligent buildings: an overview", Energy and Buildings, Vol. 223, p. 110192.

Obrecht, T.P., Kunič, R., Jordan, S. and Dovjak, M. (2019), “Comparison of health and well-being aspects in building certification schemes", Sustainability, Vol. 11 No. 9, p. 2616.

Omar, O. (2018), "Intelligent building, definitions, factors and evaluation criteria of selection", Alexandria Engineering Journal, Vol. 57 No. 4, pp. 2903-2910.

Rawte, R. (2017), "The role of ICT in creating intelligent, energy efficient buildings", Energy Procedia, Vol. 143, pp. 150-153.

Rönka, E. (2019), "Rethinking smart buildings: real estate as an active contributor to business success", Corporate Real Estate Journal, Vol. 9 No. 2, pp. 111-120.

Tham, K.W. (2016), "Indoor air quality and its effects on humans - a review of challenges and developments in the last 30 years", Energy and Buildings, Vol. 130, pp. 637-650.

Wang, N., Phelan, P.E., Gonzales, J., Harris, C., Henze, G.P., Hutchinson, R., Langevin, J., Lazarus, M.A., Nelson, B., Pyke, C., Roth, K., Rouse, D., Sawyer, K. and Selkowitz, S. (2017), "Ten questions concerning future buildings beyond zero energy and carbon neutrality", Building and Environment, Vol. 119, pp. 169-182.

Verbeke, S., Aerts, D., Rynders, G. and Ma, Y. (2020), "3rd Interim Report of the 2nd Technical Support Study on the Smart Readiness Indicator for Buildings", VITO and Waide Strategic Efficiency Europe.

Wong, J.W., Li, H. and Wang, S.W. (2005), "Intelligent building research: a review”, Automation in Construction, Vol. 4 No. 1, pp. 143-159.

Xu, J., Chen, K., Zetkulic, A.E., Xue, F., Lu, W. and Niu, Y. (2019), "Pervasive sensing technologies for facility management: a critical review", Facilities, Vol. 38 Nos 1/2, pp. 161-180.

\section{Further reading}

Kwon, M., Remøy, H., van den Dobbelsteen, A. and Knaack, U. (2019), "Personal control and environmental user satisfaction in office buildings: results of case studies in The Netherlands", Building and Environment, Vol. 149, pp. 428-435.

\section{Corresponding author}

Laura Remes can be contacted at: laura.remes@aalto.fi

For instructions on how to order reprints of this article, please visit our website: 